\title{
Distribution characteristics and source apportionment of polycyclic aromatic hydrocarbons (PAHs) in the Liao River drainage basin, northeast China
}

\author{
Jian Hu • Congqiang Liu • Guoping Zhang • \\ Yanlin Zhang • Siliang Li • Zhiqi Zhao • Baojian Liu • \\ Qinjun Guo
}

Received: 31 December 2014 / Accepted: 20 January 2016/Published online: 14 March 2016

(C) Springer International Publishing Switzerland 2016

\begin{abstract}
The Liao River drainage basin, which is one of China's seven major rivers basins, is located in northeast China. This region is characterized by important industrial bases including steel factories and oil and chemical plants, all of which have the potential to contribute pollutants to the drainage basin. In this study, 16 polycyclic aromatic hydrocarbons (PAHs) in water and suspended particulate matter (SPM) in the major rivers of the Liao River drainage basin were identified and quantified by gas chromatography mass spectrometry (GC/MS). The total PAH concentrations ranged from 0.4 to $76.5 \mu \mathrm{g} / \mathrm{g}$ (dry weight) in SPM and 32.6 to $108 \mathrm{ng} / \mathrm{L}$ in surface water, respectively. Low-ring PAHs (including two- and three-ring PAHs) were dominant in all PAH samples, and the level of low-ring PAHs in surface water was higher than that in SPM. The proportion of two-ring PAHs was the highest, accounting for an average of $68.2 \%$ of the total PAHs in surface water, while the level of three-ring PAHs was the highest in SPM, with an average of $66.3 \%$. When compared with
\end{abstract}

J. Hu $(\bowtie) \cdot$ C. Liu $\cdot$ G. Zhang $\cdot$ S. Li $\cdot$ Z. Zhao

State Key Laboratory of Environmental Geochemistry, Institute of Geochemistry, Chinese Academy of Sciences, No.46 Guanshui Road, Guiyang, Guizhou 550002, People's Republic of China e-mail: hujian@vip.skleg.cn

Y. Zhang $\cdot$ B. Liu

University of Chinese Academy of Sciences, Beijing 100049, China

Q. Guo

Institute of Geographic Sciences and Resources Research, Chinese Academy of Sciences, Beijing 10049, People's Republic of China other river systems, the concentrations of PAHs in the Liao River drainage basin were lower. Identification of the emission sources based on diagnostic ratios suggested petroleum and fossil fuel combustion were important contribution to PAHs in the study area.

Keywords Liao River drainage basin · PAHs · Emission sources $\cdot$ Diagnostic ratio

\section{Introduction}

Polycyclic aromatic hydrocarbons (PAHs) are a class of chemicals characterized by two or more condensed aromatic rings (IARC 2001) that can be emitted during incomplete combustion associated with natural processes such as volcanic eruptions and forest fires, as well as anthropogenic sources such as coal, oil, and wood combustion; therefore, they are ubiquitous in the environment. Because of their ubiquitous nature and because some are highly carcinogenic or mutagenic, PAHs have attracted a great deal of attention (Menzie et al. 1992; Rogge et al. 1993; Yu 2002; Orecchio 2010).

Rivers are a very important water resource for living, industry, and agriculture. Owing to their low aqueous solubility and hydrophobic nature, PAHs tend to associate with particulate material, which will finally be deposited into the underlying sediments in aquatic environments (Tolosa et al. 1996; Johnsen et al. 2005). The studies of concentrations and distribution of PAHs were mainly focused on coastal water and sediments in the past (Dickhut et al. 2000; Wang et al. 2001; Mai et al. 2002; Yim et al. 
2005; Frenna et al. 2013; Bergamasco et al. 2014), while few investigated have been conducted to access the distribution and accumulation of PAHs in inland rivers (Manoli et al. 2000; Chen et al. 2004; Patrolecco et al. 2010). Moreover, there is little information regarding PAH pollution in surface water and suspended particulate matter (SPM), especially in northeast China.

The Liao River drainage basin, which is one of China's seven major river basins, is located in the southwestern portion of northeast China (Fig. 1), between $\mathrm{N} 40^{\circ} 30^{\prime}$ and $\mathrm{N} 45^{\circ} 10^{\prime}$ and $\mathrm{E} 117^{\circ} 00^{\prime}$ and $\mathrm{E} 125^{\circ} 30^{\prime}$. The catchment area is about $229,000 \mathrm{~km}^{2}$, and the drainage includes two systems, the Liao River water system (East Liao River and West Liao River) and the Daliao water system (Hun River, Taizi River and Daliao River). The Xi La Mu Lun River and Lao Ha River are the main branches of the West River. The West Liao River and East Liao River meet in the northeast at the junction of Inner Mongolia Province, Liao Ning Province and Ji Lin Province, after which the river is referred to as the Liao River. The river then flows to the Liaodong Bay in the Bohai Sea. The Hun and Taizi Rivers combine to form the Daliao River, which flows to the sea.
The Liao River drainage basin passes through large industrial cities in northeast China that contain steel factories as well as oil and chemical plants, such as TongLiao, Fushun, Yingkou, Shenyang, Benxi, Liaoyang, and Anshan. With the revitalization of heavy industry in the northeast in the last two decades, pollutant emissions have been steadily increasing, and river pollution is becoming increasingly severe. PAHs can reach aquatic environments in different ways, including atmospheric deposition, urban runoff, municipal and industrial effluents, and oil spillage or leakage. Pollution of rivers and lakes with PAHs is becoming more serious, especially in urban areas and around cities (Du 2004). Although there have been some investigations of water quality in the Liao River drainage basin (Qin et al. 2013), few have focused on PAHs.

This paper presents a comprehensive survey of PAHs in water and SPM of the Liao drainage basin that covers the Liao River and Daliao water systems. The main goals of this study were to (1) identify the PAH concentration distribution in the Liao River drainage basin; (2) assess the level of contamination in the Liao River

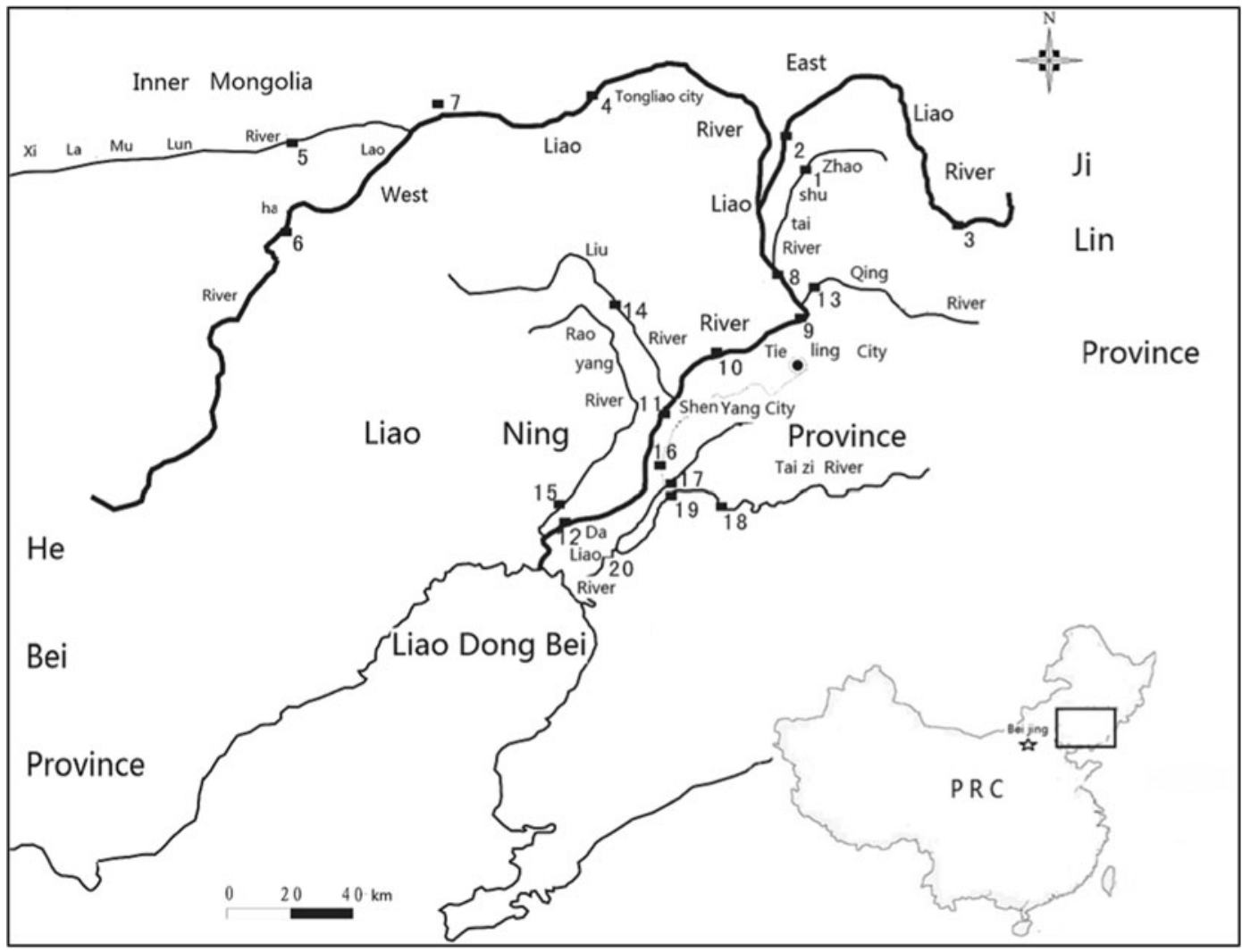

Fig. 1 The studied area and sampling locations in the Liao River drainage basin, China 
drainage basin; and (3) identify their possible sources based on molecular diagnostic ratios.

\section{Materials and methods}

Sample collection and treatment

The main streams of the Liao River drainage basin, including the East Liao River, West Liao River, and Da Liao River and their major tributaries, were sampled during July 2010. The subsurface water samples at $0.5 \mathrm{~m}$ depth were collected using pre-cleaned dark glass bottles, and the samples were collected from a total of 20 sites (Fig. 1). Among these sites, 1 3 were located in the East Liao River, 4 7 in the West Liao River, 8 12 in the main stream of the Liao River, 13 15 in the tributary of the Liao River, and 16 20 in the main stream and tributaries of the Da Liao River.

After sampling, water samples were transported to the laboratory within $24 \mathrm{~h}$ and filtered through $0.47-\mu \mathrm{m}$ Whatman glass fiber filters ( $\mathrm{GF} / \mathrm{F}, \varphi=47 \mathrm{~mm})$ that had been heated at $450{ }^{\circ} \mathrm{C}$ for $5 \mathrm{~h}$ to remove any possible organic matter.

The 16 PAHs measured in this study included naphthalene (Nap), acenaphthylene (Acy), acenaphthene (Ace), fluorene (Fle), phenanthrene (Phe), anthracene (Ant), fluoranthene (Fla), pyrene (Pyr), benzo[a]anthracene $(\mathrm{BaA})$, chrysene (Chr), benzo[b]fluoranthene (BbF), benzo[k]fluoranthene $(\mathrm{BkF})$, benzo [a] pyrene $(\mathrm{BaP})$, indeno[1,2,3-cd]pyrene (Ipy), dibenzo[a,h]anthracessne (DBA), and benzo[g,h,i]perylene (BPE).

The total organic carbon (TOC) in the Liao River drainage basin was determined using an Aurora $1030 \mathrm{~W}$ TOC.

\section{Sample extraction}

Dissolved phase PAHs in water samples were extracted using a solid-phase extraction (SPE) system from J. T. Baker. Prior to extraction, the J. T. Baker $\mathrm{C}_{18} \mathrm{SPE}$ cartridges were activated by washing with $5 \mathrm{~mL}$ of methanol followed by $2.5 \mathrm{~mL}$ of deionized water. Water samples were then amended with $12 \%$ methanol $(v / v)$, after which they were passed through the cartridges at a flow rate of $6 \mathrm{~mL} / \mathrm{min}$ under vacuum. Following extraction, the cartridges were dried under nitrogen, then eluted three times with $3 \mathrm{~mL}$ of dichloromethane. Next, three elutes were combined and concentrated to $2 \mathrm{~mL}$ under a gentle nitrogen stream. The solvent was subsequently exchanged for hexane by adding $10 \mathrm{~mL}$ hexane, after which the mixture was concentrated to about $0.5 \mathrm{~mL}$ by gently drying it with $\mathrm{N}_{2}$. Finally, the internal standards, fluorobiphenyl and terphenyl-d14, were added, and the samples were analyzed by GC-MS.

The suspension particle sample extractions were performed as previously described (Mai et al. 2002). Briefly, SPM-loaded filters were freeze-dried, weighed, and spiked with surrogate standards, (naphthalene-d8, acenaphthene-d10, phenanthrene-d10, chrysene-d12, and perylene-d12 as recovery surrogates), after which they were Soxhlet extracted for $48 \mathrm{~h}$ with methylene chloride $(250 \mathrm{~mL})$. Next, about $2 \mathrm{~g}$ of activated copper was added for desulfurization, after which the extracts were filtered and concentrated, and the solvent was exchanged for hexane. The hexane extract was subjected to a 1:2 alumina/silica gel glass column for clean-up and fractionation. The column was eluted with $15 \mathrm{ml}$ of hexane for aliphatic hydrocarbons, after which the aromatic fractions were successively eluted with $70 \mathrm{~mL}$ dichloromethane/hexane $(30: 70, v: v)$, and the second fraction was concentrated to $0.5 \mathrm{~mL}$ under a gentle high-purity nitrogen stream. The internal standards, fluorobiphenyl and terphenyl-d14, were added prior to instrumental analysis.

\section{Instrumental analysis}

All samples were analyzed using an Hewlett Packard 6890 (HP 6890) gas chromatography system equipped with an HP 5972 mass selective detector (MSD) operating in selective ion monitoring mode using a DB-5 capillary column $(30 \mathrm{~m} \times 0.25 \mathrm{~mm} \times 0.25 \mu \mathrm{m})$. Splitless injection of $1.0 \mu \mathrm{L}$ of sample was conducted using an autosampler. The GC oven temperatures were programmed to increase from 80 to $180{ }^{\circ} \mathrm{C}$ at a rate of $10{ }^{\circ} \mathrm{C} / \mathrm{min}$, then to $220^{\circ} \mathrm{C}$ at a rate of $2{ }^{\circ} \mathrm{C} / \mathrm{min}$, and finally to $290^{\circ} \mathrm{C}$ at a rate of $8{ }^{\circ} \mathrm{C} / \mathrm{min}$.

Quality control and assurance

The surrogate recoveries in all samples were 63.6 $\pm 3.5 \%$ for naphthalene-d $8,78.6 \pm 6.8 \%$ for acenaphthene-d10, 80.2 $\pm 10.1 \%$ for phenanthrene$\mathrm{d} 10,82.5 \pm 11.5 \%$ for chrysene-d12, and 76.9 $\pm 11.4 \%$ for perylene-d12. For method quality control, a procedural blank, a triplicate spiked blank, and triplicate spiked matrices were analyzed for each batch of 
samples. The mean recoveries of 16 target PAHs ranged from 75.8 to $114.3 \%$ in triplicate spiked blanks and from 60.7 to $117.5 \%$ in triplicate spiked matrices. Only trace levels of targets were detected in blanks, and these were subtracted from those in sediment samples. Detection limits were $0.01-0.02 \mathrm{ng} / \mathrm{g}$ dry weight for PAHs (defined as $\mathrm{S} / \mathrm{N}>3$ ).

Statistical analysis

Statistical analysis was done with Grapher 10.0, SPSS Statistics 19.0.0, and Microsoft Excel for Windows 7. For all the analyses, the relationships between different parameters were considered statistically significant when $p<0.05$.

\section{Results and discussion}

Contents of dissolved phase PAHs in water

The concentrations of PAHs in surface water from the Liao River drainage basin at different sampling sites are shown in Table 1. The total PAH concentrations in water ranged from 32.6 to $108.5 \mathrm{ng} / \mathrm{L}$, with an average concentration of $55.7 \mathrm{ng} / \mathrm{L}$. Only lower-ring PAHs were detected in water samples, and the average concentration of Nap was the highest. No BbF, BkF, BaP, Ipy, DBA, or BPE were detected in water samples (Table 2).

As shown in Table 3, the average concentrations of the total PAHs in water from the West Liao River watershed East Liao River watershed, Liao River main stream, Liao River branch, and Da Liao River watershed were 93.0, 68.9, 36.2, 43.6, and $44.5 \mathrm{ng} / \mathrm{L}$, respectively. The differences of PAHs levels in the water and in the SPM in the Liao River drainage basin are shown in Fig. 3 (Data were analyzed and tested using $t$ test statistical analyses by SPSS Statistics 19.0.0). The concentrations of PAHs in water in the West Liao River and East Liao River, which were located in the northern part of the Liao River drainage basin, were higher than that in the main stream of the Liao River drainage basin, the tributary of Liao River, and the Da Liao River watershed in the southern part. The concentrations of PAHs in water in the West Liao River were significantly higher than that in other rivers, and the concentrations of PAHs in the Liao River drainage basin, Liao River branch, and the Da Liao River watershed in the southern part had little difference. During the sampling period, the amounts of PAHs detected decreased along the river due to the dilution of river water. As shown in Fig. 2, the concentrations of PAHs were very high at site 7 , which was located in a farmland area from an underground in the West Liao River, and the sewage after irrigation may be the main pollution maker (Table 4).

\section{Contents of PAHs in SPM}

The concentrations of PAHs in SPM from assessed sites in the river drainage basin are shown in Table 2. The total PAH concentrations in SPM ranged from 0.4 to $76.5 \mu \mathrm{g} / \mathrm{g}$, with an average concentration of $34.2 \mu \mathrm{g} / \mathrm{g}$. It was found that total PAH concentrations in SPM in the West Liao River were significantly higher than that in other rivers as shown in Fig. 3, and the total PAH concentrations in SPM in other rivers had no obvious difference. The total PAH concentrations in SPM from different rivers occurred in the following order: West Liao River $(37.8 \mu \mathrm{g} / \mathrm{g})>$ main stream of the Liao River $(5.5 \mu \mathrm{g} / \mathrm{g})>$ Liao River branch $(5.3 \mu \mathrm{g} / \mathrm{g})>$ Da Liao River $(5.1 \mu \mathrm{g} / \mathrm{g})>$ East Liao River $(2.7 \mu \mathrm{g} / \mathrm{g})$.

As shown in Fig. 2, higher concentrations were observed at site $4(76.5 \mu \mathrm{g} / \mathrm{g})$ and site $7(49.9 \mu \mathrm{g} /$ $\mathrm{g})$, which are located in the main stream of the West Liao River near Tong Liao City. The West Liao River watershed is a branch of the Liao River with important industrial bases including oil, chemical, and steel factories in the southeast region of Inner Mongolia of China, as well as large industrial cities such as Chi Feng and Tong Liao. The industrial and domestic wastewater in Inner Mongolia was mainly discharged into the West Liao River catchments.

The PAH concentrations in water and SPM were lower than expected, during the flood season, they are also diluted by water current erosion. Accordingly, it can be concluded that PAHs in rivers mainly exist in the SPM.

\section{PAH composition in water and SPM}

The composition of PAHs by ring size along the river is shown in Fig. 4. The water and SPM mainly contained 


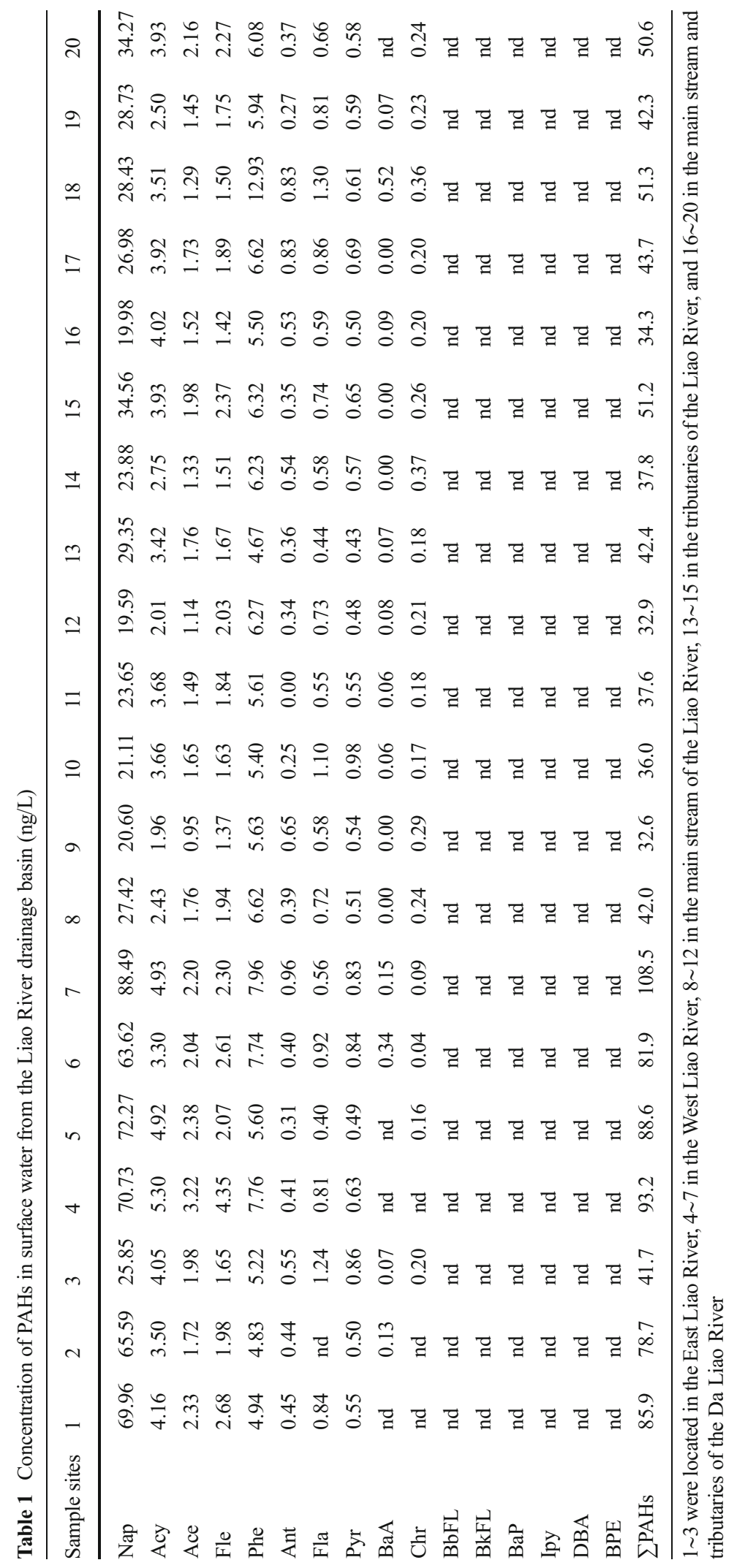




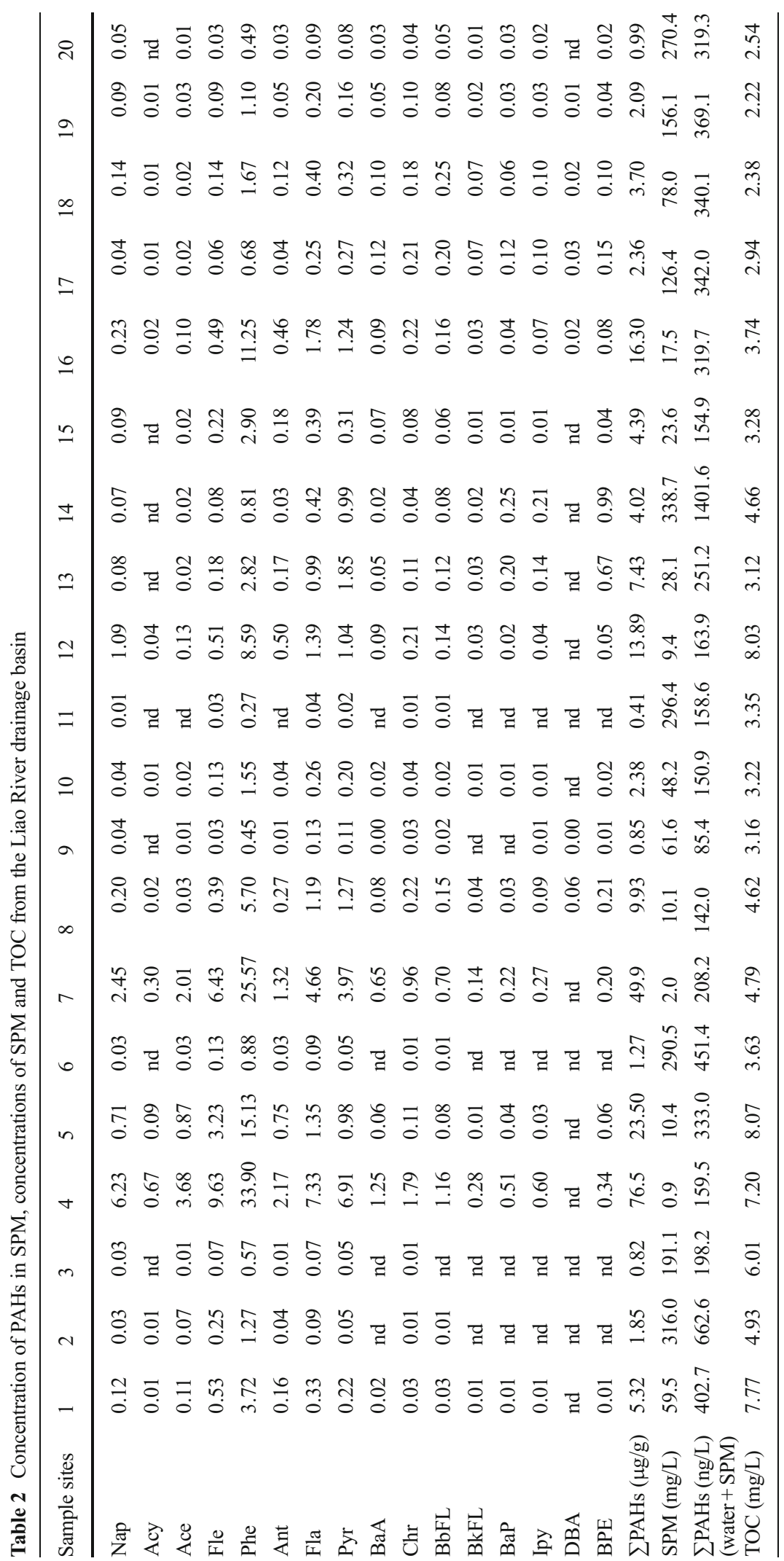


Table 3 Summary of concentration of PAHs in surface water, SPM, and TOC concentration from the Liao River drainage basin

\begin{tabular}{|c|c|c|c|c|c|}
\hline Sample sites & $\begin{array}{l}\text { The East Liao } \\
\text { River }(1-3)\end{array}$ & $\begin{array}{l}\text { The West Liao } \\
\text { River (4-7) }\end{array}$ & $\begin{array}{l}\text { The main stream of } \\
\text { the Liao River }(8-12)\end{array}$ & $\begin{array}{l}\text { Tributaries of } \\
\text { Liao River } \\
(13-15)\end{array}$ & $\begin{array}{l}\text { Da Liao } \\
\text { River (16-20) }\end{array}$ \\
\hline Mean of SPM (mg/L) & 67.3 & 75.9 & 85.1 & 130.1 & 129.7 \\
\hline Mean of $\sum$ PAHs in surface water $(\mathrm{ng} / \mathrm{L})$ & 68.9 & 93.0 & 36.2 & 43.6 & 44.5 \\
\hline Mean of $\sum$ PAHs in SPM $(\mu \mathrm{g} / \mathrm{g})$ & 2.7 & 37.8 & 5.5 & 5.3 & 5.1 \\
\hline Mean of TOC (mg/L) & 6.2 & 5.9 & 4.5 & 3.7 & 2.8 \\
\hline
\end{tabular}

low molecular weight PAHs (2-3-ring). Among individual PAHs in water samples (Fig. 4a), two-ring PAHs were most abundant. On average, two-ring PAHs accounted for 55 to $95 \%$ of the total PAHs, with a mean percentage of $68.2 \%$, while three-ring PAHs accounted for 15.7 to $39.1 \%$ of the total, with a mean percentage of $28.4 \%$. Conversely, no high molecular weight PAHs (5-6-ring) were detected in water samples. Different sites had different dominant compounds which come from different source with different composition characteristic of PAHs. In the East Liao River and West Liao River, the very higher concentration of individual PAHs Nap, Phe, and Acy were observed at sites 1, 3, 4, and 5, respectively. In the Da Liao River basin, high concentrations of Nap, Phe, and Acy were found at sites 18 and 20.

PAHs in SPM also primarily consisted of lowerringed PAHs. Among individual PAHs in SPM samples (Fig. 4b), three-ring PAHs were most abundant, ranging from 23.3 to $89.0 \%$ with a mean percentage of $66.28 \%$. Among high-ring PAHs, four-ring PAHs were most abundant, ranging from 9.6 to $40.4 \%$ with a mean percentage of $22.4 \%$. Low molecular weight PAHs (2-3-ring) accounted for 19.7 to $93.2 \%$ of the total PAHs, with a mean percentage of $30.4 \%$, except for sites 13,14 , and 17, where high molecular weight PAHs (4-6-ring) accounted for 56.0 to $74.8 \%$ of the total PAHs. These findings indicate that low molecular weight PAHs are present in greater abundance than high molecular weight PAHs in SPM samples, possible because the relatively recent local source of PAHs. Low molecular weight PAHs dissolved more easily than higher weight PAHs, while high molecular weight PAHs tend to associated with the surface of fine particles and aggregated in sediments, which leads to low molecular weight PAHs higher in SPM samples. (Zhu et al. 2004). There was a great river flood in the Liao River drainage basin during the sampling time in 2012. Maybe the flood changed the state of water column process including dissolution, adsorption, and deposition which were also the lead to the results.

As shown in Table 5, the total concentrations of PAHs in the SPM in the Liao River drainage basin are higher than that in the Chesapeake Bay and Mississippi River in the USA, as well as the Seine River in France, while it is obviously lower than that in the Tonghui, Hai, Gaoping, and Jiulong Rivers in China and the Gomti
Fig. 2 The total PAHs concentrations in water and SPM in Liao River drainage basin

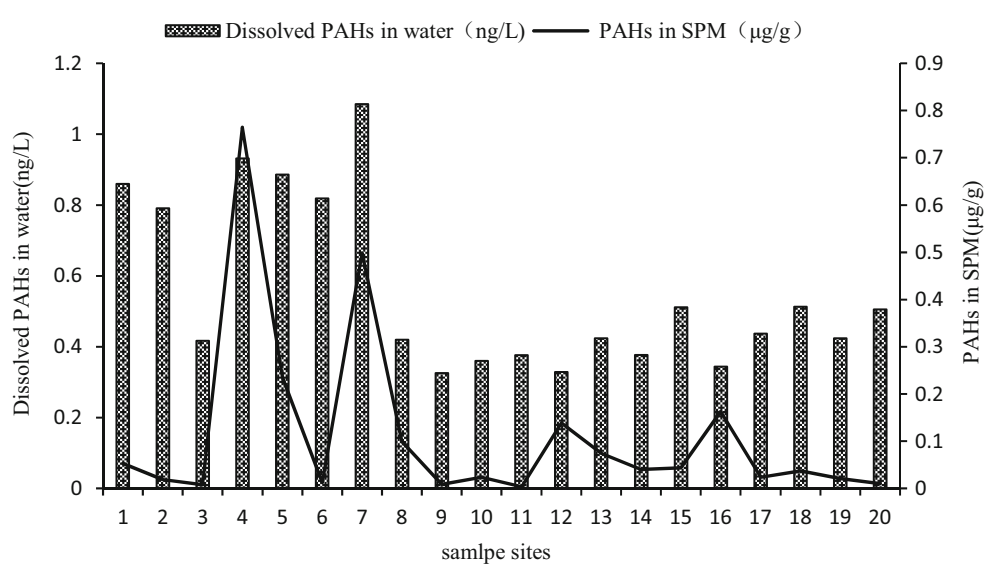


Table 4 Comparison of the P-PAHs concentrations in this study with the other urban areas in worldwide.

\begin{tabular}{llll}
\hline Locations & PAHs & LPAHs range (ng/L) & Reference \\
\hline Yellow River, China & 16 & $179 \sim 369$ & Li et al. 2006 \\
Tonghui River, China & 16 & $192.5 \sim 2651.9$ & Zhang et al. 2004 \\
Haihe River & 16 & $1800 \sim 35,000$ & Cao et al. 2005 \\
Luanhe River & 16 & $9.75 \sim 309.75$ & Li et al. 2010 \\
Chaibai River & 16 & $45.81 \sim 1272$ & Shi et al. 2005 \\
Taizi River & 16 & $367 \sim 5,94.5$ & Song et al. 2013 \\
Gaoping River, Taiwan & 16 & $10 \sim 9400$ & Doong and Lin 2004 \\
Jiulong River & 16 & $6960 \sim 26,920$ & Maskaoui et al. 2002 \\
Qiantang River & 16 & $70.3 \sim 1844.4$ & Chen et al. 2004 \\
Danube River & 16 & $25 \sim 1208$ & Nagy et al. 2013 \\
Chesapeake Bay, USA & 17 & $20 \sim 67.5$ & Gustafson and Dickhut 1997 \\
Mississippi River & 18 & $11.7 \sim 434$ & Mitra and Bianchi 2003 \\
Seine River, France & 12 & $6 \sim 36$ & Fernandes et al. 1997 \\
Gomti River, India & 16 & $60 \sim 84,210$ & Malik et al. 2011 \\
Liaohe River & 16 & $85.36 \sim 1401.61$ & This study
\end{tabular}

Fig. 3 The total PAHs

concentrations in water and SPM in the different rivers in the Liao River drainage basin. WLR Western Liao River, ELR Eastern Liao River, DLRT Da Liao River and its branches, $B L R$ branches of Liao River, $M L R$ main streams of Liao River
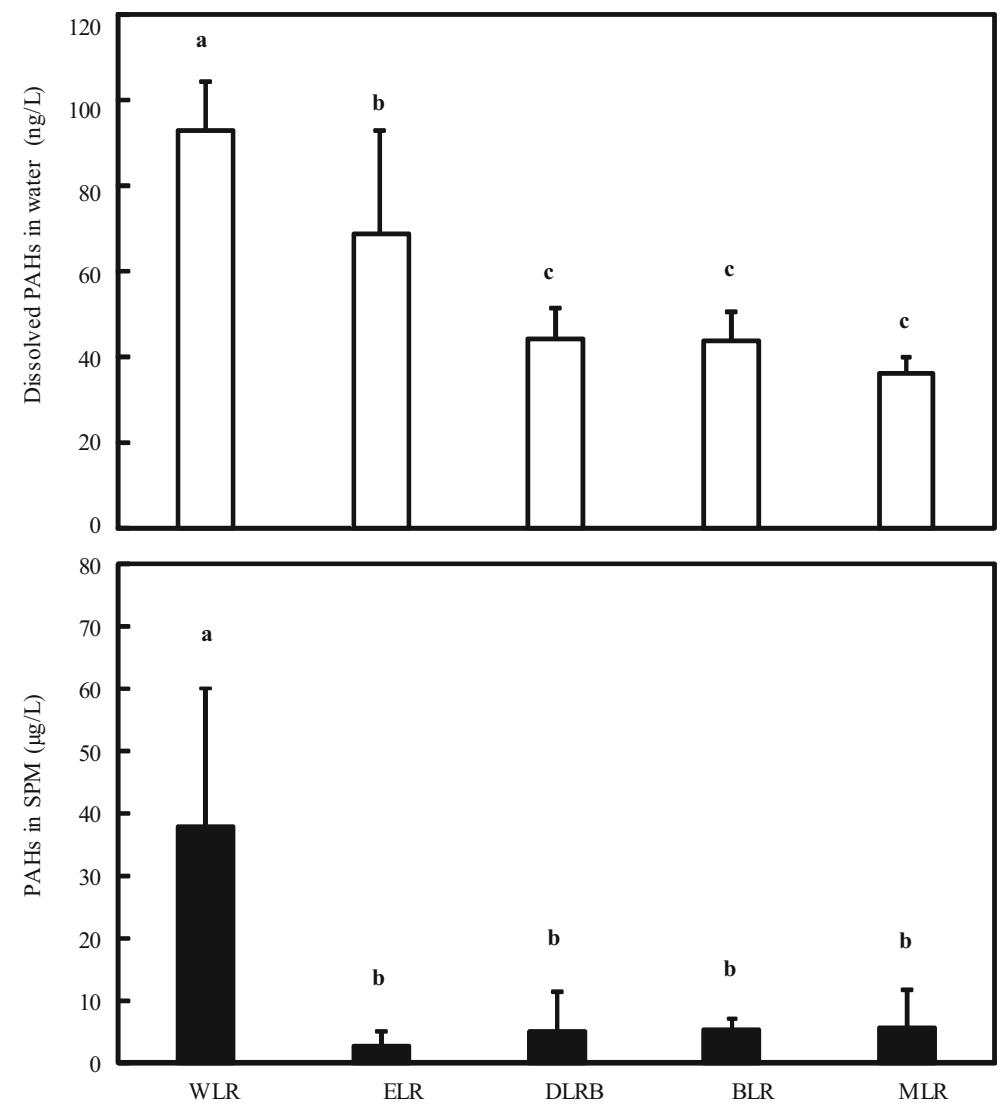
Fig. 4 Composition pattern of PAHs in water and in SPM

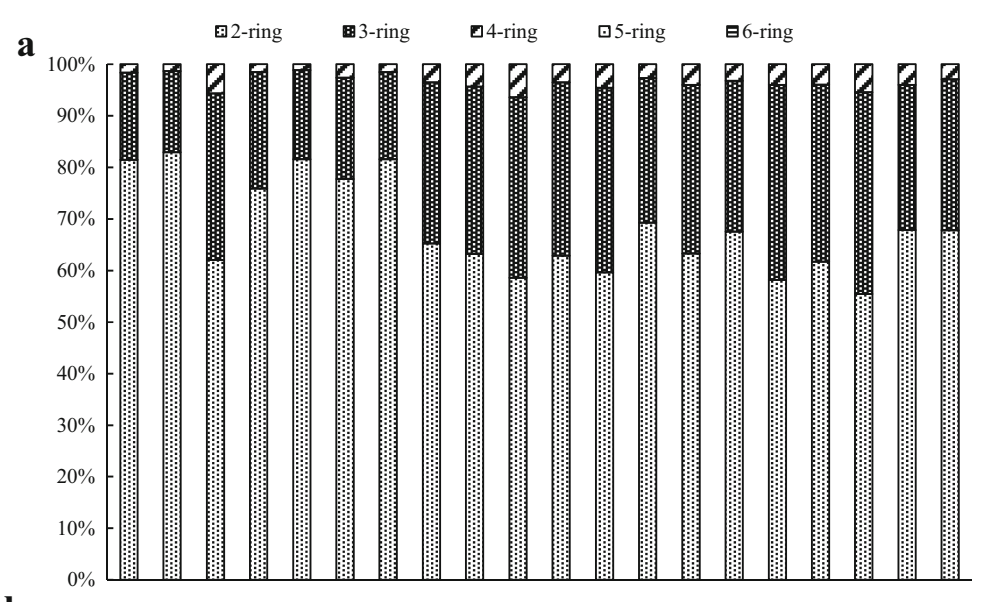

b

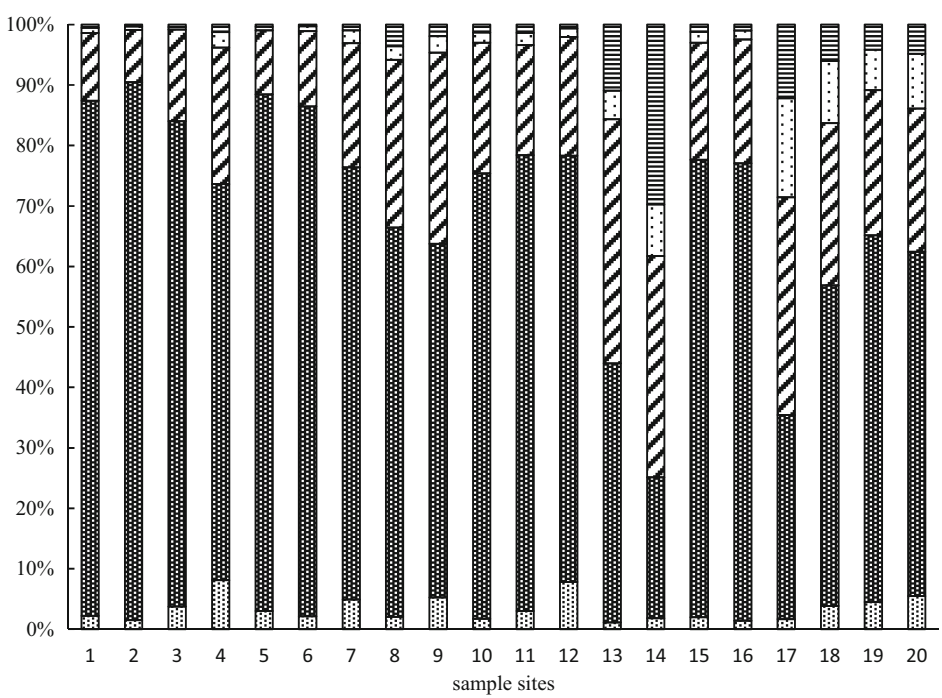

River in India (Maskaoui et al. 2002; Doong et al. 2004; Zhang et al. 2004; Cao et al. 2005; Malik et al. 2011). Additionally, the level of PAHs in the Liao River drainage basin is close to that in the Qian Tang and Chaobai rivers in China. When compared with rivers in the rest of the world, the level of pollution in the Liao River Basin is relatively low.

\section{Relationship of PAH contents with TOC of samples}

In this study, the relationship between the concentrations of PAHs and the physicochemical parameter of samples has been analyzed as shown in Table 5. The results showed a positive correlation between the total PAH concentrations both in water and SPM with TOC content. A negative correlation between the total PAH concentrations in SPM with SPM concentrations. Moreover, no correlation was observed between the total dissolved PAHs in water and the SPM concentrations. The result indicated PAHs and TOC in the Liao River drainage basin system originated from the same sources and that TOC content was an important controlling factor in PAHs partitioning and transformation in the Liao River drainage basin.

Emission sources of PAHs in the Liao River drainage basin

Understanding the sources of PAHs is very important for transport and fate of PAHs in the environment. Ratios of specific individual PAHs are characteristic of different sources (Simcik et al. 1999; Zhang and Tao 2008). The ratios of BaA/Chr, IPy/BPE, Fla/(Fla + Pyr), Phe/Ant, and $\mathrm{BaP} / \mathrm{BPE}$ were used to identify the possible origins of PAHs in SPM in this study, while only Fla/ (Fla + Pyr) and Phe/Ant were used to identify the origins 
Table 5 Correlation between TOC and $\sum$ PAHs in water and SPM

\begin{tabular}{lllll}
\hline & TOC & $\sum$ PAHs-S & $\sum$ PAHs-D & SPM \\
\hline TOC & 1 & $0.463^{*}$ & $0.453^{*}$ & -0.286 \\
$\sum$ PAHs-S & & 1 & $0.613^{* *}$ & $-0.475^{*}$ \\
$\sum$ PAHs-D & & & 1 & $-\mathrm{s} 0.103$ \\
SPM & & & & 1 \\
\hline
\end{tabular}

$\sum P A H s-S$ total PAHs in SPM, $\sum P A H s-D$ total dissolved PAHs in waters, $S P M$ total content of suspended particular matters

*Correlation is significant at the 0.05 level (two-tailed)

**Correlation is significant at the 0.01 level (two-tailed)

of PAHs in water because of their detection limits. The ranges and mean values of these ratios are presented in Table 6, together with those of other studies (Khalili et al. 1995; Simcik et al. 1999; Yunker et al. 2002; Doong and Lin 2004; Fang et al. 2004; Barreca et al. 2014; Orecchio et al. 2010).

Ratios of $\mathrm{BaA} / \mathrm{Chr}$ of $1.0-1.2$ indicate coal combustion, 0.7 indicates coke oven operation, and $0.3-1.2$ reflects gasoline, $0.2-0.4$ diesel, and 0.9 wood combustion. In this study, the ratio ranged from 0.4 to 0.9 with a mean of 0.5 , suggesting that gasoline was the dominant source of PAHs in SPM at the study sites.

The mean Phe/Ant ratio was 0.8 , and the range was 0.08-4.0 for SPM, suggesting that the PAHs originated from coal combustion, gasoline, and diesel. The ratio of $\mathrm{Fla} /(\mathrm{Fla}+\mathrm{Pyr})$ ranged from 0.3 to 0.7 , with a mean value of 0.5 for the SPM, indicating that they originated from diesel combustion. The ratios of BaP/BPE ranged from 0.1 to 1.5 , with a mean value of 0.6 , which indicated that they originated from diesel combustion.
For the PAHs in the surface water, the ratio of Fla/ (Fla $+\mathrm{Pyr}$ ) ranged from 0.4 to 0.7 , with a mean value of 0.6. This ratio was similar to that in SPM and indicated that some of the PAHs originated from diesel combustion. The ratio of Phe/Ant varied from 8.0 to 21.7, with a mean value of 14.7 , which suggested an origin of gasoline combustion.

Taken together, these findings indicate that the PAHs in the Liao River drainage basin came from a variety of sources and that gasoline and diesel combustion are important sources of PAHs in this region.

\section{Conclusions}

In this study, 16 PAHs in water and SPM in the major rivers of the Liao River drainage basin which is located in the northeast of China were identified and quantified. The $\sum_{16}$ PAHs concentrations ranged from 32.6 to $108 \mathrm{ng} / \mathrm{L}$ in surface water and 0.4 to $76.5 \mu \mathrm{g} / \mathrm{g}$ in SPM (dry weight), respectively. The $\sum_{16}$ PAHs concentrations in water in the East Liao River and West Liao River were higher than that in the main stream of the Liao River drainage basin and the Da Liao River. The $\sum_{16}$ PAHs concentrations in SPM occurred in the following order: West Liao River $(37.8 \mu \mathrm{g} / \mathrm{g})>$ main stream of the Liao River $(5.5 \mu \mathrm{g} / \mathrm{g})>$ Da Liao River $(5.1 \mu \mathrm{g} / \mathrm{g})>$ East Liao River $(2.7 \mu \mathrm{g} / \mathrm{g})$. It was found that the PAHs levels both in the water and in the SPM in the West Liao River were significantly higher than that in other rivers. Low-ring PAHs were dominant in all PAHs samples, and the level of low-ring PAHs in

Table 6 Summary of diagnostic indicators

\begin{tabular}{llllll}
\hline & BbFl/BkFl & Fla/(Fla + Pyr) & BaA/Chr & Phe/Ant & BaP/BPE \\
\hline Coal & $3.30+0.17$ & 0.74 & $1.0-1.2$ & 3 & $0.9-6.6$ \\
Coke oven & - & - & 0.7 & 0.79 & 5.1 \\
Gasoline & - & - & $0.28-1.20$ & $3.4-8$ & $0.3-0.4$ \\
Diesel & - & $0.65 \pm 0.05$ & $0.17-0.36$ & $7.6-8.8$ & $0.46-0.81$ \\
Firewood & $0.92 \pm 0.16$ & - & 0.93 & - & - \\
This study & & & & & $0.13-1.49$ \\
SPM & $3.09-7.41$ & $0.30-0.65$ & $0.38-0.9$ & $0.08-4.0$ & 0.64 \\
Mean & 4.13 & 0.54 & 0.52 & 0.81 & $7.97-21.7$ \\
In water & & $0.40-0.67$ & & 14.7 & \\
Mean & & 0.55 & & \\
\hline
\end{tabular}

Sources: Khalili et al. 1995; Simcik et al.1999; Fang et al. 2004; Doong et al. 2004; Yunker et al. 2002 
surface water was higher than that in SPM. The proportion of two-ring PAHs was the highest, accounting for an average of $68.2 \%$ of the total PAHs in surface water, while the level of three-ring PAHs was the highest in SPM, with an average of $66.3 \%$. When compared with other river systems, levels of PAHs in the Liao River drainage basin were lower than many other rivers worldwide. Ratio analysis revealed that PAHs in the Liao River drainage basin came from a variety of sources in the study area, including gasoline and diesel combustion.

Acknowledgments This work was supported by the National Grand Science and Technology Special of China through grant 2012ZX07503-003-001, the National Natural Science Foundation of China through grant 40703021 and the Chinese Academy of Sciences for Key and Innovation Projects through grant KZCX2EW-102. We also thank Professor Bixian Mai's team in Guangzhou for their assistance with laboratory analysis.

\section{References}

Barreca, S., Bastone, S., Caponetti, E., Chillura Martino, D. F., \& Orecchio, S. (2014). Determination of selected polyaromatic hydrocarbons by gas chromatography-mass spectrometry for the analysis of wood to establish the cause of sinking of an old vessel (Scauri wreck) by fire. Microchemical Journal, 117(1), 116-121.

Bergamasco, A., Culotta, L., De Stefano, C., Orecchio, S., Sammartano, S., Barreca, S., et al. (2014). Composition, distribution and sources of polycyclic aromatic hydrocarbons in sediments of the Gulf of Milazzo (Mediterranean Sea, Italy). Polycyclic Aromatic Compounds, 34(4), 397-424.

Cao, Z., Wang, Y., Ma, Y., Xu, Z., Shi, G., Zhuang, Y., Zhu, T., et al. (2005). Occurrence and distribution of polycyclic aromatic hydrocarbons in reclaimed water and surface water of Tianjin, China. Journal of Hazardous Materials, 122(1-2), 51-59.

Chen, B., Xuan, X., Zhu, L., Wang, J., Gao, Y., Yang, K., Lou, B., et al. (2004). Distributions of polycyclic aromatic hydrocarbons in surface waters, sediments and soils of Hangzhou City, China. Water Research, 38(16), 3558-3568.

Dickhut, R. M., Canuel, E. A., Gustafson, K. E., Liu, K., Arzayus, K. M., Walker, S. E., MacDonald, E. H., et al. (2000). Automotive sources of carcinogenic polycyclic aromatic hydrocarbons associated with particulate matter in the Chesapeake Bay Region. Environmental Science \& Technology, 34(21), 4635-4640.

Doong, R. A., \& Lin, Y. T. (2004). Characterization and distribution of polycyclic aromatic hydrocarbon contaminations in surface sediment and water from Gao-ping River, Taiwan. Water Research, 38(7), 1733-1744.
Du, Q. G. (2004). Stratagem study on sustainable development and environmental protection in Liaoning province (1st Edn., pp. 11-15). Beijing: Science (in Chinese).

Fang, G.-C., Chang, C.-N., Wu, Y.-S., Fu, P. P.-C., Yang, I. L., Chen, M.-H., et al. (2004). Characterization, identification of ambient air and road dust polycyclic aromatic hydrocarbons in central Taiwan, Taichung. Science of the Total Environment, 327(1-3), 135-146.

Fernandes, M. B., Sicre, M.-A., Boireau, A., \& Tronczynski, J. (1997). Polyaromatic Hydrocarbon (PAH) distributions in the Seine River and its Estuary. Marine Pollution Bulletin, 34(11), 857-867.

Frenna, S., Mazzola, A., Orecchio, S., Tuzzolino, N., et al. (2013). Comparison of different methods for extraction of polycyclic aromatic hydrocarbons (PAHs) from Sicilian (Italy) coastal area sediments. Environmental Monitoring and Assessment, 185(7), 5551-5562.

Gustafson, K. E., \& Dickhut, R. M., (1997). Distribution of polycyclic aromatic hydrocarbons in Southern Chesapeake Bay surface water: evaluation of three methods for determining freely dissolved water concentrations. Environmental Toxicology and Chemistry, 16(12), 452-461.

IARC (2001). Monographs programme on the evaluation of carcinogenic risks to humans, Lyon, France.

Johnsen, A. R., Wick, L. Y., Harms, H., et al. (2005). Principles of microbial PAH-degradation in soil. Environmental Pollution, 133(1), 71-84.

Khalili, N. R., Scheff, P. A., Holsen, T. M., et al. (1995). PAH source fingerprints for coke ovens, diesel, and gasoline engines, highway tunnels, and wood combustion emissions. Atmospheric Environment, 29(4), 533-542.

Li, G., Xia, X., Yang, Z., Wang, R., \& Voulvoulis, N. (2006). Distribution and sources of polycyclic aromatic hydrocarbons in the middle and lower reaches of the Yellow River, China. Environmental Pollution, 144(3), 985-993.

Li, Y., Liu, J., Cao, Z., Lin, C., \& Yang, Z. (2010). Spatial distribution and health risk of heavy metals and polycyclic aromatic hydrocarbons (PAHs) in the water of the Luanhe River Basin, China. Environmental Monitor Assessment, 163(1), 1-13.

Mai, B.-X., Fu, J.-M., Sheng, G.-Y., Kang, Y.-H., Lin, Z., Zhang, G., Zeng, E. Y., et al. (2002). Chlorinated and polycyclic aromatic hydrocarbons in riverine and estuarine sediments from Pearl River Delta, China. Environmental Pollution, 117(3), 457-474.

Malik, A., Verma, P., Singh, A., Singh, K., et al. (2011). Distribution of polycyclic aromatic hydrocarbons in water and bed sediments of the Gomti River, India. Environmental Monitoring and Assessment, 172(1-4), 529-545.

Manoli, E., Samara, C., Konstantinou, I., Albanis, T., et al. (2000). Polycyclic aromatic hydrocarbons in the bulk precipitation and surface waters of Northern Greece. Chemosphere, 41(12), 1845-1855.

Maskaoui, K., Zhou, J. L., Hong, H. S., Zhang, Z. L., et al. (2002). Contamination by polycyclic aromatic hydrocarbons in the Jiulong River Estuary and Western Xiamen Sea, China. Environmental Pollution, 118(1), 109-122.

Menzie, C. A., Potocki, B. B., Santodonato, J., et al. (1992). Exposure to carcinogenic PAHs in the environment. Environmental Science \& Technology, 26(7), 1278-1284. 
Mitra, S., \& Bianchi, T. (2003). A preliminary assessment of polycyclic aromatic hydrocarbondistributions in the lower Mississippi River and Gulf of Mexico. Marine Chemistry, 82(3), 273-288.

Nagy, A. S., Simon, G., Szabó, J., Vass, I., et al. (2013). Polycyclic aromatic hydrocarbons in surface water and bed sediments of the Hungarian upper section of the Danube River. Environmental Monitoring and Assessment, 185(6), 46194631.

Orecchio, S. (2010). Assessment of polycyclic aromatic hydrocarbons (PAHs) in soil of a natural reserve (Isola delle Femmine) (Italy) located in front of a plant for the production of cement. Journal of Hazardous Materials, 173(1-3), 358-368.

Orecchio, S., Cannata, S., Culotta, L., et al. (2010). How building an underwater pipeline connecting Libya to Sicilian coast is affecting environment: polycyclic aromatic hydrocarbons (PAHs) in sediments; monitoring the evolution of the shore approach area of the Gulf of Gela (Italy). Journal of Hazardous Materials, 181(1-3), 647-658.

Patrolecco, L., Ademollo, N., Capri, S., Pagnotta, R., Polesello, S., et al. (2010). Occurrence of priority hazardous PAHs in water, suspended particulate matter, sediment and common eels (Anguilla anguilla) in the urban stretch of the River Tiber (Italy). Chemosphere, 81(11), 1386-1392.

Qin, R., Wu, Y., Xu, Z., Xie, D., Zhang, C., et al. (2013). Assessing the impact of natural and anthropogenic activities on groundwater quality in coastal alluvial aquifers of the lower Liaohe River Plain, NE China. Applied Geochemistry, 31, 142-158.

Rogge, W. F., Hildemann, L. M., Mazurek, M. A., Cass, G. R., Simoneit, B. R. T., et al. (1993). Sources of fine organic aerosol. 2. Noncatalyst and catalyst-equipped automobiles and heavy-duty diesel trucks. Environmental Science \& Technology, 27(4), 636-651.

Shi, Z., Tao, S., Pan, B., Fan, W., He, X. C., Zuo, Q., et al. (2005). Contamination of rivers in Tianjin, China by polycyclic aromatic hydrocarbons. Environmental Pollution, 134(1), 97-111

Simcik, M. F., Eisenreich, S. J., \& Lioy, P. J. (1999). Source apportionment and source/sink relationships of PAHs in the coastal atmosphere of Chicago and Lake Michigan. Atmospheric Environment, 33(30), 5071-5079.

Song, X. Y., Hu, X. J., He, M. M., Liang, R. J., Li, Y. S., Li, F. M., et al. (2013). Distribution and sources of polycyclic aromatichydrocarbons in the surface water of Taizi River, Northeast of China. Environmental Monitoring and Assessment, 185(10), 8375-8382.

Tolosa, I., Bayona, J. M., Albaigés, J., et al. (1996). Aliphatic and polycyclic aromatic hydrocarbons and sulfur/oxygen derivatives in Northwestern Mediterranean sediments: spatial and temporal variability, fluxes, and budgets. Environmental Science \& Technology, 30(8), 2495-2503.

Wang, X. C., Zhang, Y. X., Chen, R. F., et al. (2001). Distribution and partitioning of polycyclic aromatic hydrocarbons (PAHs) in different size fractions in sediments from Boston Harbor, United States. Marine Pollution Bulletin, 42(11), 1139-1149.

Yim, U. H., Hong, S. H., Shim, W. J., Oh, J. R., Chang, M., et al. (2005). Spatio-temporal distribution and characteristics of PAHs in sediments from Masan Bay, Korea. Marine Pollution Bulletin, 50(3), 319-326.

Yu, H. (2002). Environmental carcinogenic polycyclic aromatic hydrocarbons: photochemistry and phototoxicity. Journal of Environmental Science and Health. Part C, Environmental Carcinogenesis \& Ecotoxicology Reviews, 20(2), 149-183.

Yunker, M. B., Macdonald, R. W., Vingarzan, R., Mitchell, R. H., Goyette, D., Sylvestre, S., et al. (2002). PAHs in the Fraser River basin: a critical appraisal of PAH ratios as indicators of PAH source and composition. Organic Geochemistry, 33(4), 489-515.

Zhang, Y., \& Tao, S. (2008). Seasonal variation of polycyclic aromatic hydrocarbons (PAHs) emissions in China. Environmental Pollution, 156(3), 657-663.

Zhang, Z., Huang, J., Yu, G., Hong, H., et al. (2004). Occurrence of PAHs, PCBs and organochlorine pesticides in the Tonghui River of Beijing, China. Environmental Pollution, 130(2), 249-261.

Zhu, L. Z., Chen, B. L., Wang, J., Shen, H. X., et al. (2004). Pollution survey of polycyclic aromatic hydrocarbons in surface water of Hangzhou, China. Chemosphere, 56(11), 1085-1095. 